\title{
PHẪU THUẬT ĐIỀU TR!̣ BỆNH VAN HAI LÁ TRÊN BỆNH NHÂN NHỒI MÁU NÃO
}

Bùi Minh Thành*, Lê Thị Hồng Khánh*, Hoàng Quốc Hoà*

\section{TÓM TẮT}

Nghiên cứu hồi cứu 39 bệnh nhân mắc bệnh van hai lá đã có biến chứng nhồi máu não được phẫu thuật tại Khoa Phẫu Thuật Tim Bệnh viện Nhân Dân Gia Định từ tháng 4/2013 đến tháng 12/2017. Tuổi trung bình $50,3 \pm 7,56$, thời gian mắc nhồi máu não $8,2 \pm 11,2$ tháng, NYHA II và III-IV lần lượt là $38,5 \%$ và $10,3 \%$. Yếu liệt chi chiếm $83,8 \%$, liệt $0 / 5$ chiếm $39,8 \%$. Rung nhĩ gặp $88,2 \%$, chỉ số tim-ngực là $0,58 \pm 0,08$, BNP 1989 $\pm 1156 \mathrm{pg} / \mathrm{ml}$. Hẹp hai lá $94,8 \%$, hở hai lá $48,7 \%$, huyết khối buồng tim $28,2 \%$, diện tích van $0,7 \pm$ $0,19 \mathrm{~cm}^{2}$, LA: $53,6 \pm 7,9 \mathrm{~mm}$, LVDd: 41,3 $\pm 3,6$ mm, PAPs: $66,5 \pm 17,8 \mathrm{mmHg}$. Tổn thương não bán cấp hay mãn (MSCT hoặc MRI) gặp 100\%. Thời gian tuần hoàn ngoài cơ thể $83,18 \pm 15,65$ phút, thời gian cặp ĐMC 50,53 $\pm 11,15$ phút, thời gian thông khí cơ học 11,52 $\pm 6,12$ giờ, thời gian hồi sức sau mổ $69,74 \pm 31,54$ giờ. Tai biến thường gặp sau mổ là cơn nhịp nhanh thất $(12,8 \%)$ và động kinh cục bộ gặp $15,4 \%$, Không xuất hiện tai biến mạch máu não sau mổ, không có trường hợp nào tử vong.

Key word: Hẹp hở hai lá, Rung nhĩ, huyết khối trong tim, nhồi máu não, thay van hai lá, sữa van hai lá.

\section{SUMMARY}

SURGICAL TREATMENT OF THE MITRAL VALVE DISEASE ON THE PATIENT WITH CEREBRAL INFARCTION

Bui Minh Thanh, Le Thi Hong Khanh, Hoang Quoc Hoa

Department of cardiac surgery, Nhan Dan Gia Dinh Hospital, Ho Chi Minh City

Retrospective study was done on 39 patients acquired mitral valvular stenosis and/or regurgitation with documented stroke in history who underwent surgery in Cardiac surgery department from April 2013 to December 2017. Average age 50,3 \pm 7,56, duration since ischemic stroke 8,2 \pm 11,2 months, NYHA II and III-IV are consecutively $38,5 \%$ and 10,3\%. Extremities paralyses accounts for $83,8 \%, 0 / 5$ paralyses are $39.8 \%$. AF is $88,2 \%$, cardiac-thorax index is 0,58 \pm 0,08, BNP: $1989 \pm 1156 \mathrm{pg} / \mathrm{ml}$. Mitral stenosis got $94,8 \%$, mitral regurgitation 48,7\%, intracardiac thrombi $28,2 \%$, valvular surface 0,7 $\pm 0,19 \mathrm{~cm}^{2}$, LA dimension: 53,6 \pm 7,9 mm, LVDd: 41,3 \pm 3,6 mm, PAPs: 66,5 $\pm 17,8 \mathrm{mmHg}$. Subacute cerebral or chronic cerebral lesions are totally 100\% (MSCT or MRI). Cardial pulmonary bypass time is within 83,18 $\pm 15,65$ minutes, aortic clampage is ranged 50,53 $\pm 11,15$ minutes, mechanical ventilation 11,52 $\pm 6,12$ hours, postoperative resusitation time 69,74 $\pm 31,54$ hours. Post-op common complication are supraventricular tachycardia (12,8\%) and local seizure which is seen in 15,4\%. No recurrent ischemic stroke or death documented.

Keyword: mitral insufficience, atrial fibrillation, intracardiac thrombi, ischemic stroke, mitral valvular replacement, mitralplasty.

\section{I. ĐẶT VẤN ĐỀ}

Tai biến mạch máu não (TBMMN) là một bệnh lý thường gặp, do nhiều nguyên nhân, có tỷ lệ tử vong và tàn phế cao. Ở Mỹ, một năm có hơn nửa triệu bệnh nhân mới xuất hiện và là nguyên

* Khoa Phẫu thuật Tim, BV Nhân dân Gia Định Người chịu trách nhiệm khoa học: PGS.TS. Hoàng Quốc Hoà Ngày nhận bài: 01/05/2018 - Ngày Cho Phép Đăng: 20/05/2018

Phản Biện Khoa học: GS.TS. Bùi Đức Phú PGS.TS. Đặng Ngọc Hùng 
nhân tử vong đứng hàng thứ ba [6][4]. Do đó việc lượng giá trước những nguyên nhân và yếu tố nguy cơ để phòng ngừa bệnh là vấn đề quan trọng hàng đầu hiện nay.

Theo các tiêu chuẩn chẩn đoán hiện nay, nhồi máu não có nguyên nhân từ tim trong khoảng 3-8\% các bệnh nhân đột quỵ [15][17] và một trong những nguyên nhân thường gặp của nhồi máu não do thiếu máu não cục bộ là thuyên tắc từ tim chiếm khoảng 10-20\%, đặc biệt nếu kèm rung nhĩ [17][5][20]. Rung nhĩ lại thường gặp trong bệnh lý hẹp van hai lá, đặc biệt là hẹp khít, gây huyết khối nhĩ trái [2][7][10][13][17] [23].

- Điều trị nội khoa bệnh lý van hai lá trong bệnh cảnh này chỉ là điều trị bảo tồn, điều trị triệu chứng [17][24][28][32][38]. Điều trị ngoại khoa có tính chất triệt để hơn: thay hoặc sửa van hai lá, lấy huyết khối trong các buồng tim, kết hợp điều trị phá rung nhĩ, điều trị kháng đông nhằm phòng ngừa biến chứng lấp mạch não tái phát [12][14][16][18][19][21] [25].

Tại Bệnh viện Nhân dân Gia định, chúng tôi đã thực hiện phẫu thuật điều trị ngoại khoa bệnh van hai lá trên những bệnh nhân có nhồi máu não bán cấp / cũ. Do vậy, đề tài này được thực hiện, nhằm:

- Tìm hiểu đặc điểm lâm sàng và cận lâm sàng của bệnh lý này.

- Đánh giá vai trò của điều trị phẫu thuật, kết quả điều trị ngoại khoa bệnh van hai lá trên bệnh nhân có nhồi máu não.

- Đề xuất một số phương án điều trị đối với nhóm bệnh nhân thương tổn đa cơ quan này.

\section{II. ĐỐI TƯợNG - PHƯƠNG PHÁP NGHIÊN CÚU}

\section{1. Đối tượng nghiên cứu:}

- Tiêu chuẩn chọn bệnh: Tất cả các bệnh nhân mắc bệnh van hai lá (hẹp - hở) có tiền căn nhồi máu não bán cấp / cũ được phẫu thuật tại Khoa Phẫu thuật tim Bệnh viện Nhân dân Gia định, từ tháng 04/2012 đến tháng 12/2017.

- Tiêu chuẩn loại trừ: Bệnh nhân có kèm bệnh lý van động mạch chủ hay bệnh lý mạch vành cần phẫu thuật

- Số lượng bệnh nhân: $\mathrm{n}=39$.

\subsection{Phương pháp nghiên cứu.}

- Thống kê mô tả, tiền cứu và hồi cứu.

- Lập phiếu nghiên cứu, thu thập các số liệu. Xử lý số liệu theo phần mềm STATA 12.0

- Tất cả các bệnh nhân được can thiệp phẫu thuật van hai lá có nhồi máu não trước đó đều được nghiên cứu về :

* Tiền sử bệnh: thấp khớp, suy tim sung huyết, phù phổi cấp, ho ra máu, rung nhĩ, tăng huyết áp, đái đường, bệnh thận mãn, điều trị tiêu sợi huyết, tai biến mạch máu não...

* Lâm sàng: Các triệu chứng cơ năng, các mức độ suy tim theo phân độ NYHA, yếu liệt chi, mức độ liệt $0 / 5$, thời gian mắc nhồi máu não.

* Cận lâm sàng: ECG, Chỉ số tim/ngực trên $\mathrm{X}$ quang, MSCT não hay MRI não, chụp mạch vành, siêu âm Doppler các thân $\mathrm{ĐM}$ trên quai ĐMC, Pro-BNP.

* Siêu âm tim:

+ Đánh giá các tổn thương van, mức độ hẹp, hở van, Huyết khối trong nhĩ. Các tổn thương phối hợp khác nếu có.

+ Phân suất tống máu (EF), áp lực động mạch phổi (ALĐMP), diện tích van hai lá, các thông số các buồng tim nhĩ trái, thất trái.

Phẫu thuật có hỗ trợ tuần hoàn ngoài cơ thể (THNCT):

* Kết quả về THNCT: thời gian chạy THNCT, thời gian cặp động mạch chủ (ĐMC), áp lực ĐMC trong chạy THNCT.

* Các phương pháp phẫu thuật : Thay van, sửa van, phẫu thuật phối hợp, các loại tổn thương trên van tim. 
* Hồi sức tim: Thời gian thông khí cơ học hỗ trợ, thời gian điều trị tại hồi sức tim

Đánh giá sau phẫu thuật:

* Tai biến, biến chứng sớm, cải thiện liệt 0/5.

* Lâm sàng: Độ suy tim (NYHA)

* Phân suất tống máu, áp lực động mạch phổi sau phẫu thuật.

* Theo dõi sau mổ, biến chứng muộn.

* Tử vong bệnh viện.

\section{KẾT QUẢ}

\section{1. Đặc điểm chung:}

Tổng số bệnh nhân: 39

Độ tuổi trung bình: $50.3 \pm 7.56(36$ - 73)

Tỉ lệ về giới: Nữ / Nam = 2,55 (28/11)

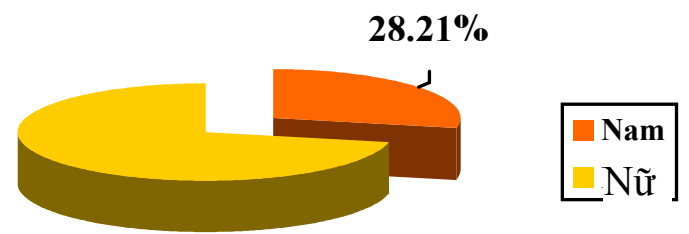

$71.79 \%$

\section{Biểu đồ 1.Phân bố bệnh nhân theo giới}

\section{2. Đặc điểm bệnh lý:}

\subsubsection{Tiền sủ bệnh nhân:}

Bảng 3.1. Tiền sử của bệnh nhân:

\begin{tabular}{|l|c|c|}
\hline \multicolumn{1}{|c|}{ Tiền sử bệnh } & n & \% \\
\hline Thấp khớp (tim) & 26 & 66,7 \\
\hline Tăng huyết áp & 4 & 10,3 \\
\hline Rối loạn lipid máu & 7 & 17,9 \\
\hline Bệnh thận mãn & 5 & 12,8 \\
\hline Đái đường & 3 & 7,7 \\
\hline Phù phổi cấp & 15 & 38,5 \\
\hline Nhồi máu não $(*)$ & 39 & 100 \\
\hline Điều trị tiêu sợi huyết & 4 & 10,3 \\
\hline Lao & 1 & 2,6 \\
\hline
\end{tabular}

(*): Tất cả bệnh nhân đều bị nhồi máu não

\subsubsection{Lâm sàng:}

* Triệu chứng lâm sàng

Bảng 3.2. Triệu chúng lâm sàng

\begin{tabular}{|l|c|c|}
\hline \multicolumn{1}{|c|}{ Triệu chứng } & n & \% \\
\hline Hồi hộp - Đau ngực & 39 & 100 \\
\hline Khó thở các mức độ & 31 & 79,5 \\
\hline Ho ra máu & 11 & 28,2 \\
\hline Ngất & 8 & 20,5 \\
\hline Rung nhĩ trước mổ & 34 & 88,2 \\
\hline Suy tim các mức độ & 39 & 100 \\
\hline Yếu liệt chi & 33 & 83,8 \\
\hline Liệt 0/5 & 16 & 39,8 \\
\hline
\end{tabular}

* Đánh giá suy tim theo NYHA

Bảng 3.3. Các mức độ suy tim theo NYHA

\begin{tabular}{|c|c|c|}
\hline Độ suy tim & $\mathrm{n}$ & $\%$ \\
\hline NYHA I & 0 & 0 \\
\hline NYHA II & 20 & 51,2 \\
\hline NYHA III & 15 & 38,5 \\
\hline NYHA IV & 4 & 10,3 \\
\hline
\end{tabular}

* Thời gian mắc nhồi máu não:

$8,2 \pm 11,2$ tháng $(1,5-71)$

\subsubsection{Cận lâm sàng:}

Bảng 3.4. Thông số cận lâm sàng chính

\begin{tabular}{|l|c|c|}
\hline \multicolumn{1}{|c|}{ Cận lâm sàng } & n & \% \\
\hline MSCT/MRI sọ não $\left({ }^{\mathrm{a}}\right)$ & 39 & 100 \\
\hline Chụp mạch vành $\left(^{\mathrm{b}}\right)$ & 27 & 69,2 \\
\hline Siêu âm mạch cảnh $\left(^{\mathrm{c}}\right)$ & 39 & 100 \\
\hline Cấy máu $\left(^{\mathrm{d}}\right)$ & 7 & 17,9 \\
\hline BNP & $1989 \pm 1156 \mathrm{pg} / \mathrm{ml}$. \\
\hline Chỉ số tim ngực & \multicolumn{2}{|c|}{$0,58 \pm 0,08$} \\
\hline
\end{tabular}

( ${ }^{\mathrm{a})}$ MSCT hoặc MRI não: có thương tổn não.

( $\left.{ }^{b}\right)$ Không hẹp có ý nghĩa

$\left(^{c}\right)$ Siêu âm kiểm tra thân các ĐM trên quai ĐMC:

không có thương tổn

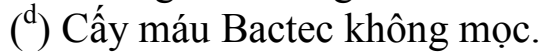

3.2.4. Siêu âm tim:

a) Tổn thương các van tim

Bảng 3.5. Tỉ lệ tổn thương các van phối hợp

\begin{tabular}{|l|c|c|}
\hline \multicolumn{1}{|c|}{ Van tim thương tổn } & n & \% \\
\hline Hẹp hai lá khít & 20 & 51,3 \\
\hline Hẹp - hở hai lá $(1,5-2,5 / 4)$ & 17 & 43,5 \\
\hline Hở - hẹp hai lá vừa & 2 & 5,1 \\
\hline Hở ba lá nặng $(\geq 3 / 4)$ & 34 & 87,2 \\
\hline Hở ba lá vừa $(2-2,5 / 4)$ & 5 & 12,8 \\
\hline
\end{tabular}


b) Phân suất tống máu (FE)

FE trung binh: $52.6 \pm 6.5$ (\%) (42 - 70\%).

Bảng 3.6. Phân bố các trị số FE

\begin{tabular}{|l|c|c|}
\hline Phân suất tống máu FE & $\mathrm{n}$ & $\%$ \\
\hline FE $\leq 30$ & 0 & 0 \\
\hline FE $30-50$ & 25 & 64,1 \\
\hline FE $>50$ & 14 & 35,9 \\
\hline
\end{tabular}

c) Áp lực động mạch phổi (ALĐMP)

ALĐMP trung bình: 66,5 17,8 mmHg (30-95 mmHg)

Bảng 3.7. Phân bố các mức độ tăng ALĐMP

\begin{tabular}{|l|c|c|}
\hline \multicolumn{1}{|c|}{ ALĐMP $(\mathrm{mmHg})$} & $\mathrm{n}$ & $\%$ \\
\hline Tăng nhẹ-vừa $(\leq 60 \mathrm{mmHg})$ & 18 & 46,2 \\
\hline Tăng nặng $(>60 \mathrm{mmHg})$ & 21 & 53,8 \\
\hline Tồng cộng & 39 & 100 \\
\hline
\end{tabular}

d) Các đánh giá siêu âm tim khác

Bảng 3.8: Kết quả siêu âm trước mổ

\begin{tabular}{|l|c|}
\hline Siêu âm tim & Giá trị \\
\hline Huyết khối nhĩ trái & $28,2 \%$ \\
\hline SMV $(\mathrm{cm} 2)\left({ }^{\mathrm{a}}\right)$ & $0,7 \pm 0,19$ \\
\hline LVEDd $(\mathrm{mm})\left(^{\mathrm{b}}\right)$ & $41,3 \pm 3,6$ \\
\hline LVEDs $(\mathrm{mm})\left(^{\mathrm{c}}\right)$ & $30,04 \pm 3,95$ \\
\hline LA $(\mathrm{mm})\left({ }^{\mathrm{d}}\right)$ & $53,6 \pm 7,9$ \\
\hline ALĐMP & $66,5 \pm 17,8$ \\
\hline
\end{tabular}

( ${ }^{\text {a) }}$ SMV: diện tích van hai lá.

(b) LVEDd: đường kính thất trái cuối tâm trương

( ) LVEDs: đường kính thất trái cuối tâm thu

$\left.{ }^{(}\right)$LA: nhĩ trái.

\subsubsection{Kết quả phẫu thuạt:}

a. Phuơng pháp mổ

Bảng 3.9. Phân bố phương pháp mổ phối hợp

\begin{tabular}{|l|c|c|}
\hline Phương pháp mổ & $\mathrm{n}$ & $\%$ \\
\hline Thay van hai lá & 1 & 2,6 \\
\hline Sữa van hai lá & 2 & 5,1 \\
\hline Thay hai lá + sữa ba lá & 32 & 84,7 \\
\hline Sữa hai lá + sữa ba lá & 3 & 7,7 \\
\hline Tổng cộng & 39 & 100 \\
\hline
\end{tabular}

Phương pháp mổ chủ yếu là thay van hai lá phối hợp sữa ba lá và lấy huyết khối làm sạch buồng tim

b. Tuần hoàn ngoài co thể (THNCT) và Hồi súc tim (HST):

\begin{tabular}{|l|c|}
$\begin{array}{l}\text { Bảng 3.10. Phân bố thời gian THNCT\& Hồi } \\
\text { súc tim }\end{array}$ \\
\hline THNCT \& HST & phút \\
\hline Thời gian THNCT & $83.18 \pm 16,65$ \\
\hline Thời gian cặp ĐMC & $50,53 \pm 11,15$ \\
\hline Thời gian hỗ trợ CEC & $26,47 \pm 6,3$ \\
\hline Thông khí cơ học hỗ trợ & $11,52 \pm 6,12$ \\
\hline Thời gian hồi sức tim & $69,74 \pm 31,54$ \\
\hline
\end{tabular}

HA trung bình/CEC: $64,5 \pm 4,7$ mmHg

c. Thuơng tổn van tim ghi nhận trong mổ

\section{Bảng 3.11. Các dạng thuơng tổ van tim ghi} nhận trong mổ

\begin{tabular}{|l|c|c|}
\hline \multirow{2}{*}{ Dạng thương tổn } & \multicolumn{2}{|c|}{ Van hai lá } \\
\cline { 2 - 3 } & $\mathrm{n}$ & $\%$ \\
\hline Dính mép van & 39 & 100 \\
\hline Viêm dày lá van & 33 & 84,6 \\
\hline Co rút BMDV(*) & 34 & 87,1 \\
\hline Thủng cánh van & 3 & 7,7 \\
\hline Đứt thừng gân & 4 & 10,3 \\
\hline Vôi hóa lá van-vòng van & 33 & 84,6 \\
\hline Sa lá van & 6 & 15,4 \\
\hline Sùi trên lá van & 7 & 17,9 \\
\hline
\end{tabular}

(*): BMDV: Bộ máy dưới van 2 lá

\section{d. Các kỹ thuật khác phối hợp}

Bảng 3.12. Các kỹ thuật khác phối hợp

\begin{tabular}{|l|c|c|}
\hline \multicolumn{1}{|c|}{ Kỹ thuật } & $\mathrm{n}$ & $\%$ \\
\hline $\begin{array}{l}\text { Lấy huyết khối nhĩ trái - Đóng } \\
\text { tiểu nhĩ trái }\end{array}$ & 11 & 28,2 \\
\hline Sữa van phối & 3 & 7,7 \\
\hline Đóng đường dò mạch vành & 3 & 7,7 \\
\hline Đóng lỗ bầu dục rộng & 4 & 10,3 \\
\hline
\end{tabular}


e. Kết quả phẫu thuật.

Bảng 3.13. Tai biến - biến chúng trong và sau phẫu thuật

\begin{tabular}{|l|c|c|}
\hline \multicolumn{1}{|c|}{ Tai biến - biến chứng } & $\mathrm{n}$ & $\%$ \\
\hline Mở ngực lại cầm máu & 0 & 0 \\
\hline Chảy máu $>1500 \mathrm{ml} / 12 \mathrm{~h}$ & 0 & 0 \\
\hline Hội chứng cung lượng tim thấp & 3 & 7,7 \\
\hline Thông khí hố trợ kéo dài $>$ 24 giờ & 3 & 7,7 \\
\hline Suy thận cấp & 2 & 5,1 \\
\hline Nhịp nhanh kịch phát trên thât & 5 & 12,8 \\
\hline Động kinh cục bộ & 6 & 15.4 \\
\hline Viêm phồi & 1 & 2,6 \\
\hline Nhồi máu cơ tim & 0 & 0 \\
\hline Tử vong bệnh viện $\left(^{*}\right)$ & 0 & 0 \\
\hline
\end{tabular}

3.2.6. Đánh giá theo dõi sau mổ:

a.Phân độ suy tim theo NYHA

Bảng 3.14. Phân độ NYHA tái khám sau sáu tháng so với trước mổ.

\begin{tabular}{|l|c|c|c|c|}
\hline \multirow{2}{*}{ Độ suy tim } & \multicolumn{2}{|c|}{ Trước PT } & \multicolumn{2}{c|}{ Sau PT } \\
\cline { 2 - 5 } & $\mathrm{n}$ & $\%$ & $\mathrm{n}$ & $\%$ \\
\hline NYHA I( $\left.{ }^{*}\right)$ & 0 & 0 & 12 & 38,5 \\
\hline NYHA II & 21 & 53,8 & 26 & 66,7 \\
\hline NYHA III(**) & 14 & 35,9 & 1 & 2,6 \\
\hline NYHA IV & 4 & 10,3 & 0 & 0 \\
\hline
\end{tabular}

$(*),(* *): \mathrm{p}<0,01$

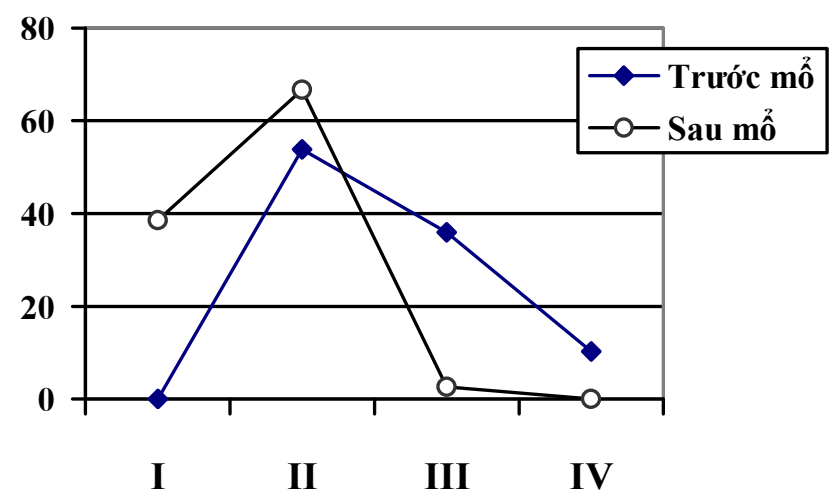

Biểu đồ 2. Sụ thay đổi NYHA trước và sau phẫu thuật

b. Thay đổi áp lục động mạch phổi(ALĐMP): ALĐMP trung binh: $30.6 \pm 6.4 \mathrm{mmHg}$
Bảng 3.15. Ap lục động mạch phổi trước và 6 tháng sau phẫu thuật (PT)

\begin{tabular}{|l|c|c|c|c|}
\hline \multirow{2}{*}{$\begin{array}{l}\text { ALĐMP } \\
(\mathrm{mmHg})\end{array}$} & \multicolumn{2}{|c|}{ Trước PT } & \multicolumn{2}{c|}{ Sau PT } \\
\cline { 2 - 5 } & $\mathrm{n}$ & $\%$ & $\mathrm{n}$ & $\%$ \\
\hline$<30$ & 0 & 0 & 13 & 33,3 \\
\hline $30-45$ & 5 & 12,8 & 20 & 51,3 \\
\hline $45-60$ & 15 & 38,5 & 6 & 15,4 \\
\hline$\geq 60$ & 19 & 48,7 & 0 & 0 \\
\hline trung bình $(*)$ & \multicolumn{3}{|c|}{$62.4 \pm 12.5$} & \multicolumn{3}{|c|}{$30.6 \pm 6.4$} \\
\hline
\end{tabular}

(*) $\mathrm{p}<0,01$

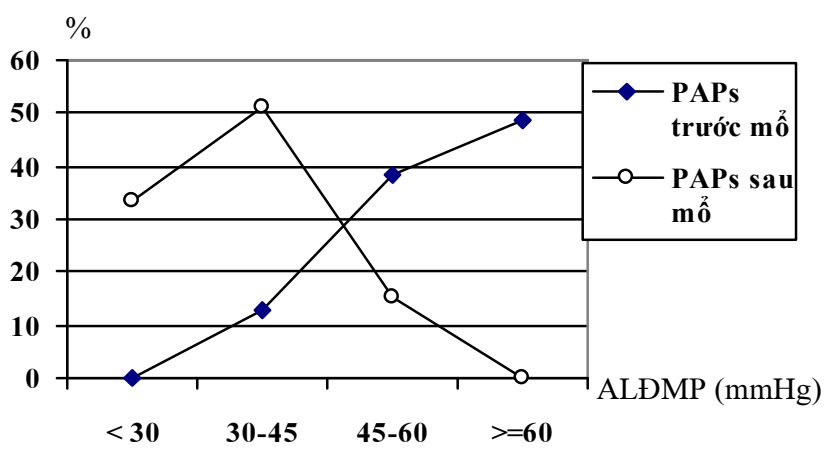

Biểu đồ 3. Sụ thay đổi ALĐMP trước và sau phẫu thuật

c. Thay đổi phân suất tống máu (EF) và mức độ liệt 0/5 truoóc- sau mổ:

Bảng 3.16: Phân suất tống máu (EF) và mức độ liệt 0/5 truớc-sau mổ.

\begin{tabular}{|l|l|l|c|}
\hline Tham số & T.mổ (\%) & S.mổ (\%) & p \\
\hline EF & $52,6 \pm 6,5$ & $63.7 \pm 8.4$ & 0,0336 \\
\hline Liệt $0 / 5$ & 35,9 & 0 & 0,0002 \\
\hline
\end{tabular}

d. Các biến chứng muộn

Bảng 3.17: Biến chứng muộn

\begin{tabular}{|l|c|c|}
\hline \multicolumn{1}{|c|}{ Biến chứng } & n & \% \\
\hline Tiểu máu do kháng đông & 3 & 7,7 \\
\hline Xuất huyết tiêu hoá nhẹ & 1 & 2,6 \\
\hline Kẹt van do thuyên tắc & 0 & 0 \\
\hline Tai biến mạch máu não & 0 & 0 \\
\hline Tắt mạch chi & 0 & 0 \\
\hline Tử vong đột ngột & 0 & 0 \\
\hline
\end{tabular}




\subsubsection{Theo dõi sau mổ}

- Thời gian theo dõi trung bình:

$27.6 \pm 11.6$ tháng $(6-48$ tháng $)$

- Phân bố tỷ lệ bệnh nhân theo dõi sau phẫu thuật

Bảng 3.18 : Phân bố tỷ lệ bệnh nhân theo dõi sau phẫu thuật

\begin{tabular}{|c|c|c|}
\hline Thời gian (tháng) & $\mathrm{n}$ & $\%$ \\
\hline $3-6$ & 4 & 10,3 \\
\hline $6-12$ & 7 & 17,9 \\
\hline $12-24$ & 15 & 38,8 \\
\hline $24-48$ & 13 & 30 \\
\hline Tổng cộng & 39 & 100 \\
\hline
\end{tabular}
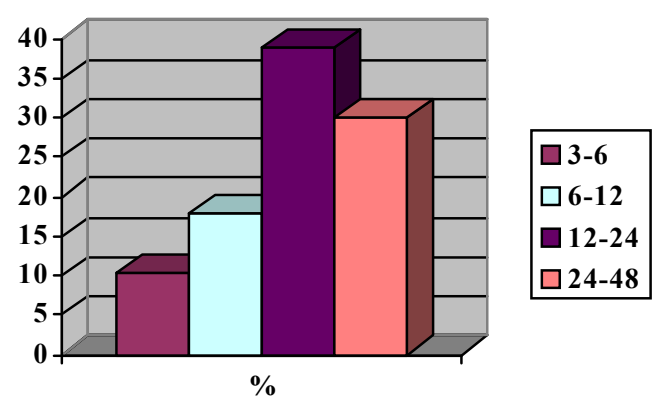

Biểu đồ 04: Phân bố tỷ lệ bệnh nhân theo dõi sau phẫu thuạt.

\section{BÀN LUẬN}

Thay hay sữa van hai lá là phẫu thuật kinh điển và thường quy trong điều trị ngoại khoa bệnh van hai lá. Tuy nhiên, phẫu thuật này trên bênh nhân có nhồi máu não thì còn nhiều cân nhắc, do bởi nhồi máu não là tai biến thường gặp, mà theo một nghiên cứu của Adams [6][40] chiếm đến $60 \%$ của các $\mathrm{TBMMN}$ và do nhiều nguyên nhân, trong đó nguyên nhân từ tim vào khoảng $1-20 \%$ theo một nghiên cứu của Furie [4][6][3].

Tìm hiểu về cơ chế bệnh sinh thường thấy là do hẹp van hai lá khít lâu ngày gây giãn nhĩ trái kèm rung nhĩ và từ đó hình thành huyết khối trong tim, theo đại tuần hoàn trôi lên não gây lấp mạch và rồi là nhồi máu não.

Do vậy, huyết khối trong tim là hậu quả tất biến của rung nhĩ mà theo nghiên cứu Leung và Davidson tìm thấy có $14 \%$ có huyết khối cấp và
$27 \%$ có huyết khối mãn trên các bệnh nhân hẹp van hai lá có rung nhĩ [8].

Trước đây, việc điều trị ở nhóm bệnh này thường là điều trị nội khoa bảo tồn là sự phối hợp giữa các phác đồ trị liệu: tiêu sợi huyết, kiểm soát huyết áp, kháng đông, kháng ngưng tập tiểu cầu và điều chỉnh lipid máu [7][11][15][36].

Tuy nhiên, căn nguyên bệnh lý vẫn luôn còn hiện hữu trong tim và muốn giải quyết được vấn đề này, chỉ bằng con đường can thiệp ngoại khoa thì triệt để hơn [18][19][21].

Theo các nghiên cứu về đột quỵ, thuyên tắc mạch tái phát xuất hiện ở 30-60\% bệnh nhân mắc bệnh van hai lá hậu thấp mà có tiền sử thuyên tắc trước đó[40][11][34]. Hẹp van hai lá hậu thấp là nguyên nhân gây tắc mạch não thường gặp nhất hơn là hở van hai lá: theo một nghiên cứu gặp ở $93 \%$ trong hẹp hai lá và chỉ có $7 \%$ trong hở van hai lá [7][17]. Hơn nữa, tắc mạch có thể xảy ra ở bệnh nhân hẹp van hai lá ở nhịp xoang bình thường, nhưng sự hình thành và phát triển của rung nhĩ làm gia tăng nguy cơ tắc mạch cao nhất [5][17]. Bên cạnh đó, tỉ lệ nhồi máu não thầm lặng chiếm khoảng 24,5\% ở nhóm bệnh hẹp van hai lá hậu thấp [43].

Những bệnh nhân, trong nhóm nghiên cứu, nhập viện để phẫu thuật thường đã có nhiều năm tháng mắc bệnh van hai lá, do thời gian mắc bệnh lâu nên thương tổn van tim rất nặng nề: cánh van xơ cứng, vôi hoá, biến dạng, loét sùi trên van, vòng van cũng vôi hoá nhiều khi giãn lớn, bộ máy dưới van co rút, phì đại và xơ hoá, nhĩ trái giãn lớn, thậm chí vôi hoá thành nhĩ, thất trái thu nhỏ, thất phải nhĩ phải giãn lớn. Do vậy, việc chỉ định thay van tim nhiều khi không cần bàn cãi, vấn đề sữa van không mấy khi thực thi, cho nên tỉ lệ thay van của chúng tôi chiếm đa số, không tuơng ứng với các tác giả Kim hay Bando [1][33][35], chủ yếu là sửa van. Tuy nhiên, trong thời gian sau mổ hai năm, các tác giả này đều ghi nhận có khoảng $20 \%$ bệnh nhân có tái xuất hiện 
các nhồi máu mới, nhưng không tìm thấy bằng chứng rõ ràng có nguồn gốc từ tim [29][31]. Theo một nghiên cứu khác, sự tồn tại của nhĩ trái lớn kèm thêm rung nhĩ làm gia tăng tần suất đột quỵ. thầm lặng ở nhóm bệnh nhân hẹp van hai lá [29][43], và ngay cả sửa van hai lá cũng không loại bỏ một cách có ý nghĩa nguy cơ tắc mạch [40][30][36].Trong quần thể bệnh nhân của chúng tôi có thể do bởi hầu hết bệnh nhân đều tuân thủ chế động kháng đông nghiêm ngặt sau mổ thay van nên phần nào hạn chế được tỉ lệ tái thành lập huyết khối do vậy hầu như chưa bắt gặp bệnh nhân tái phát nhồi máu não sau mổ (hơn nữa quần thể nghiên cứu chưa nhiều).

Rung nhĩ là một trong những nguyên nhân tạo lập huyết khối trong tim, chúng tôi bắt gặp trong $88,2 \%$ và các rung nhĩ này thường hiện hữu hầu như là mãn tính (hơn 2 năm). Sau mổ, tuy có cải thiện về lâm sàng nhưng sự cải thiện này không có ý nghĩ về mặt thống kê. so với tác giả khác, như Baek, Gilinov, hay Bando [12][27][35][37][41], vừa sữa van phối hợp với tiến trình Cox-Maze xoá rung nhĩ, nhưng sau hai năm thì có khoảng $75 \%$ còn giữ được nhịp xoang và $25 \%$ loạn nhịp trong đó có rung nhĩ..

Thủ phạm chính gây nhồi máu não là huyết khối, mà có nguồn gốc từ nhĩ trái chúng tôi tìm thấy khoảng gẩn $28,2 \%$ trong nghiên cứu này, tỉ lệ này cũng khá cao so với các tác giả Leung và Davidson hay Poungvarin [2][3][7][8] cũng như cao hơn với tỉ lệ trong một nghiên cứu ở đa van tim ở khu vực miền trung cách đây hơn 10 năm, là 18,9\%.

Mặc dù tần suất mắc bệnh thấp tim và bệnh van tim giảm đáng kể, nhưng bệnh van tim hậu thấp vẫn là nguyên nhân rất quan trọng của tắt mạch não[9][22][26], mà van hai lá thường liên quan nhất. kế đến là phối hợp của van hai lá và van chủ, trong khi đó bệnh thấp van chủ đơn độc không thường gặp. Sự phối hợp của van phổi và van ba lá lại càng hiếm gặp hơn[17].
Tăng áp phổi là đặc tính cố hữu ở nhóm bệnh hai lá này và điều này làm bệnh cảnh lâm sàng trở trầm trọng hơn đồng thời ảnh hưởng không nhỏ đến quá trình hồi sức sau mổ tim cũng như là một trong nhưng yếu tố tiên lượng bệnh.

Khác với các tác giả khác [40][44][34], trong nhóm bệnh nhân nghiên cứu, chúng tôi ghi nhận hầu hất các bệnh nhân đã bị nhồi máu não nhiều lần, ở nhiều vị trí khác nhau. Chúng tôi không đưa vào serie nghiên cứu các bệnh nhân có xuất huyết não, và sẽ đề cập trong một nghiên cứu khác. Chính sự tái phát nhồi máu não nhiều lần tiếp diễn đã làm cho bệnh cảnh lâm sàng đã nặng nề lại càng u tối hơn, làm cho bản thân bệnh nhân và thân nhân vô cùng bất an lo lắng. Điều này lại càng thôi thúc cần phải đưa ra những lý giải thuyết phục về mục đích đúng đắn của phẫu thuật.

Mục đích của phẫu thuật là: giải quyết căn nguyên nhồi máu não và tránh tái phát đồng thời không gây thêm thương tổn nhu mô não trong quá trình phẫu thuật với sự hỗ trợ của hạ thân nhiệt và tuần hoàn ngoài cơ thể. Tuy nhiên, như chúng tôi đã đề cập ở trên, một trong những rào cản khó khăn nhất là thuyết phục bệnh nhân hay thân nhân bệnh nhân đồng ý phẫu thuật, bởi do: sau nhiều lần nhồi máu não liên tiếp khiến họ nghĩ rằng mình xem như đã tàn phế, đặc biệt sự phối hợp song hành của bệnh cảnh nhồi máu não và bệnh tim trong nhiều năm tháng khiến cho sức khoẻ bệnh nhân suy sụp, niềm hy vọng về sống còn càng mong manh hơn cũng như khả năng tài chính khánh kiệt. Tôi cũng muốn chia sẻ rằng, trong thực tế chỉ có khoảng $15 \%$ bệnh nhân đồng ý phẫu thuật mà thôi.

Cho dù rằng đã có cơ sở khoa học rõ ràng để chỉ định phẫu thuật, và để quyết định phẫu thuật chúng tôi xét đến các tiêu chuẩn đôi về tim mạch và thần kinh. Về tim, dựa trên chủ yếu phân tích đánh giá về lâm sàng và siêu âm tim. Mặc khác, về phương diện thần kinh chúng tôi tham 
khảo ý kiến của chuyên khoa nội thần kinh và chẩn đoán hình ảnh, tuy nhiên, thi thoảng có những lúc không đồng quan điểm về mặt đánh giá hình ảnh học giữa hai chuyên khoa này về nhồi máu não bán cấp hay nhồi máu não mới, khiến nhiều khi cũng khá đắn đo trong vấn đề chọn thời điểm phẫu thuật.

Một số trường hợp nhồi máu não-hẹp van hai lá đã điều trị ổn nhưng còn chần chờ phẫu thuật. Nhưng rất may mắn khi mở nhĩ trái chúng tôi thấy huyết khối mới lại vừa được thành lập, ở những bệnh nhân này nếu không phẫu thuật kịp thời thì nguy cơ nhồi máu não là không tránh khỏi. Do vậy, vấn đề đặt ra là:

Từ sau khi bị nhồi máu não đến thời điểm nào thì nên phẫu thuât ? theo các đồng nghiệp trong nước thì thời gian chờ đợi này có thể giao động từ 8-12 tuần hay lâu hơn nữa. Tuy nhiên, trong thực tế nhiều khi ngày phẫu thuật đã đự̛ơ ấn định nhưng ngay trước khi mổ, thậm chí có bệnh nhân ngay đêm trước mổ, lại rơi vào cơn nhồi máu não mới, mà nhiều khi nhiều lần liên tiếp như vậy, làm phải trì hoãn cuộc mổ nhiều lần, thậm chí không còn cơ hội để phẫu thuật bệnh nhân lần nữa. Do vậy, chúng tôi đề ra nguyên tắc: Không quá sớm khi thương tổn não chưa ổn định và cũng không quá muộn để tránh nhồi máu não tái phát, thông thường tại Bệnh viện Gia Định, chúng tôi thực hiện kiểm tra MRI não khoảng 3-5 tuần một lần, nếu lâm sàng tiến triển tốt chúng tôi tiến hành phẫu thuật ngay, may ra có thể cứu được bệnh nhân.

Để tăng cường bảo về não và không gây thêm thương tổn não trong quá trình phẫu thuật dưới tuần hoàn ngoài cơ thể, chúng tôi thực hiện bảo đảm huyết áp duy trì ổn định với khoảng 15$20 \%$ mức huyết áp cao hơn thông thường trong CEC, đồng thời chế độ priming đặc biệt phối hợp hemofilter giúp duy trì áp lực keo ổn định, giữ không toan chuyển hoá và ngăn ngừa phù não trong suốt quá trình phẫu thuật. Mặt khác, các tiêu chuẩn cai $\mathrm{CEC}$ cũng cần thực hiện nghiêm ngặt về huyết động, hô hấp, nhịp, bài niệu, thân nhiệt và khí máu động mạch.

Đứng trước bệnh nhân vừa thay van vừa bị tai biến mạch máu não thì việc sử dụng kháng đông và chống ngưng tập tiểu cầu như thế nào là hợp lý và an toàn là một vấn đề cũng cần phải cân nhắc, nhất là trong giai đoạn hồi sức và hậu phẫu. Heparine liều điều trị cũng phải được dùng ngay, với việc theo dõi TCA nghiêm ngặt và sau đó relais với kháng đông AVK cũng như aspirin. Chúng tôi cũng phải duy trì trị số INR thích hợp để ngăn ngừa tắc van và đề phòng chảy máu não [42][45].

Về việc chăm sóc theo dõi sau mổ ở các bệnh nhân này nhiều lúc khá vất vả và công phu vì rằng, ngoài việc chăm sóc theo dõi của một diễn tiến hậu phẫu thay van trên bệnh nhân có suy tim, loạn nhịp, tăng áp phổi, rối lạon chức năng thất trái... mà còn phải biết theo dõi phát hiện cũng như phòng ngừa các tai biến biến chứng về thần kinh: nhồi máu não mới, xuất huyết não, hội chứng màng não hay thậm chí cả tăng áp lực sọ não.... để có hướng xử lý kịp thời.

Đặc biệt sự phục hồi liệt sau mổ khá là ngoạn mục, một phần là do sự phục hồi thương tổn não tự nhiên và một phần do bởi nguồn cơn gây nhồi máu tái phát đã bị cắt đứt cũng như tuân thủ nghiêm ngặt chế độ kháng đông chống ngưng tập tiểu cầu sau mổ.

Một vấn đề cuối cùng cũng không kém phần quan trọng là chăm sóc nuôi dưỡng sau mổ cũng như chống loét, khá nhiều bệnh nhân phải cần đến sự can thiệp của Khoa dinh dưỡng, cũng như sự tận tuỵ của đội ngũ điều dưỡng hộ lý giúp ăn uống và xoa bóp thay đổi tư thế nhiều lần trong ngày. 


\section{KẾT LUẬN}

Qua nghiên cứu 39 trường hợp can thiệp phẫu thuật van hai lá trên bệnh nhân có nhồi máu não, chúng tôi rút ra một số kết luận sau:

- Bệnh cảnh van hai lá trên bệnh nhân có nhồi máu não thường nặng nề: Suy tim, EF giảm, tăng áp phổi, suy giảm chức năng ý thức và vận động (liệt)

- Việc chọn thời điểm phẫu thuật còn nhiều cân nhắc và phụ thuộc vào nhiều yếu tố liên quan: thời gian tiềm tàng sau nhồi máu, sự cải thiện về thần kinh học và mức độ suy tim.

- Phẫu thuật giúp tránh nhồi máu não tái phát, cải thiện tình trạng bệnh lý tim mạch, tỉ lệ tử vong rất thấp $(0 \%)$ và mang lại chất lượng cuộc sống tốt hơn.

\section{TÀI LIỆU THAM KHẢO}

1. Kim JS, Lee SA, Park JB, Chee HK, Chung JW. Preoperative risk factor analysis of postoperative stroke after Cox-maze procedure with mitral valve repair. BMC Cardiovasc Disord. 2014 Sep 11;14:116.

2. Poungvarin N, Opartkiattikul N, Chaithiraphan S, Viriyavejakul A. A comparative study of coumadin and aspirin for primary cardioembolic stroke and thromboembolic preventions of chronic rheumatic mitral stenosis with atrial fibrillation. J Med Assoc Thai 1994;77:1-6.

3. Furie K, Khan M. Secondary Prevention of Cardioembolic Stroke: Pathophysiology, Diagnosis, and Management. 2016, Pages 1014-1029.

4. Guidelines for Prevention of Stroke in Patients With Ischemic Stroke or Transient Ischemic Attack A Statement for Healthcare Professionals From the American Heart Association/American Stroke Association Council on Stroke. Stroke. 2006;37:577-617.

5. Mohr JP, Caplan LR, Melski JW, Goldstein RJ, Duncan GW, Kistler JP, et al. The Harvard
Cooperative Stroke registry: A prospective study. Neurology 1978;28:754-62.

6. Furie KL, Kasner SE, Adam JR et Alts. Guiline for prevention of stroke in patients with stroke or transient ischemic attack, AHA/ASA. Stroke 2011; 42:227.

7. Fleming HA, Bailey SM. Mitral valve disease, systemic embolism and anticoagulants. Postgrad Med J 1971;47:599-604.

8. Leung DY, Davidson PM, Cranney GB, Walsh WF. Thromboembolic risks of left atrial thrombus detected by TEE. Am J Cardiol .1997; 79:626.

9. Ghandehari K, Izadi-Mood Z. Etiology of young adult onset brain infarction in Iran. Arch Iran Med 1006;9:240-3.

10. Jordan B. King PharmD. MS, Peyman N. Azadani MD , Promporn Suksaranjit MD, MS, Adam P.Bress PharmD, MS, Daniel M.Witt PharmD, Frederick T.Han MD, Mihail G.Chelu $\mathrm{MD}, \mathrm{PhD}$, Michelle A.Silver MSPH , Joseph Biskupiak PhD, MBA, Brent D.Wilson MD, $\mathrm{PhD}$, Alan K.Morris MS, Eugene G.Kholmovski PhD, Nassir Marrouche MD. Left Atrial Fibrosis and Risk of Cerebrovascular and Cardiovascular Events in Patients With Atrial Fibrillation. Journal of the American College of Cardiology, Volume 70, Issue 11, 2018, p:1311-1321

11. Carter AB. Prognosis of cerebral embolism. Lancet 1965;2:514-9.

12. Marc Gillinov MD, Adam E.Saltman MD, $\mathrm{PhD}$. Ablation of Atrial Fibrillation with Concomitant Cardiac Surgery. Seminars in Thoracic and Cardiovascular Surgery, Vol 19, Issue 11, p:25-32

13. Al-Ahmad AM, Daudelin DH, Salem DN. Antithrombotic therapy for valve disease: Native and prosthetic valves. Curr Cardiol Rep 2000;2:56-60.

14. Takashi Nitta MD, PhD. Surgery for Atrial Fibrillation: A Worldwide Review. Seminars in Thoracic and Cardiovascular Surgery, Vol 19, Issue 11, p:3-8 
15. Matsumoto N, Whisnant J, Kurland L, Okazaki H. Natural history of stroke in Rochester, Minnesota 1955-1969. Stroke 1973;4:2-29.

16. Lee CH, Kim JB, Jung SH, Choo SJ, Chung $\mathrm{CH}$, Lee JW. Left atrial appendage resection versus preservation during the surgical ablation of atrial fibrillation. Ann Thorac Surg 2014;97:124-32.

17. Caplan LR. Stroke: A clinical approach, $3^{\text {rd }}$ ed. Butterworth-Heinemann: Boston; 2000.

18. Park HC, Lee D, Shim J, Choi JI, Kim YH. The clinical efficacy of left atrial appendage isolation caused by extensive left atrial anterior wall ablation in patients with atrial fibrillation. J Interv Card Electrophysiol 2016;46:287-97.

19. Romanov A, Pokushalov E, Elesin D, et al. Effect of left atrial appendage excision on procedure outcome in patients with persistent atrial fibrillation undergoing surgical ablation. Heart Rhythm 2016;13:1803-9.

20. Cardiogenic brain embolism: The second report of the Cerebral Embolism Task Force. Arch Neurol 1989;46:727-43.

21. Lakkireddy D, Mahankali AS, Kanmanthareddy A, et al. Left atrial appendage ligation and ablation for persistent atrial fibrillation. The LAALA-AF registry. J Am Coll Cardiol EP 2015;1:153-60.

22. Constante Sotelo JL, Mendez Dominguez A. Rheumatic heart disease: Cause of cerebrovascular disease at the National Intstitute of Cardiology "Ignacio Chavez". Arch Cardiol Mex 2006;76:47-51.

23. Rillig A, Tilz RR, Lin T, et al. Unexpectedly high incidence of stroke and left atrial appendage thrombus formation after electrical isolation of the left atrial appendage for the treatment of atrial tachyarrhythmias. Circ Arrhythm Electrophysiol 2016;9:3461.

24. Stroke Prevention in Atrial Fibrillation Study Group Investigators: Preliminary report of the Stroke Prevention in Atrial Fibrillation Study. N Engl J Med 1990;322:863-8.
25. Yorgun H, Canpolat U, Kocyigit D, Coteli C, Evranos B, Aytemir K. Left atrial appendage isolation in addition to pulmonary vein isolation in persistent atrial fibrillation: oneyear clinical outcome after cryoballoon-based ablation. Europace 2017;19:758-68.

26. Chockalingam A, Gnanavelu G, Elangovan S, Chockalingam V. Clinical spectrum of chronic rheumatic heart disease in India. J Heart Valve Dis 2003;12:577-81.

27. Gillinov, A.M., Sirak, J., Blackstone, E.H., McCarthy, P.M., Rajeswaran, J., Pettersson, G. et al. The Cox maze procedure in mitral valve disease: predictors of recurrent atrial fibrillation. J Thorac Cardiovasc Surg. 2005; 130: 1653-1660

28. Stroke Prevention in Atrial Fibrillation Investigators: The stroke prevention in atrial fibrillation trial: Final results. Circulation 1991;84:527-39.

29. Lee, S.H., Kim, J.B., Cho, W.C., Chung, C.H., Jung, S.H., Choo, S.J. et al. The influence of age on atrial fibrillation recurrence after the maze procedure in patients with giant left atrium. J Thorac Cardiovasc Surg. 2011; 141: 1015-1019.

30. Deverall PB, Olley PM, Smith DR, Watson DA, Whitaker W. Incidence of systemic embolism before and after mitral valvotomy. Thorax 1968;23:530-6.

31. Kim, J.B., Moon, S.J., Yun, S.C., Kim, K.W., Jung, S.H., Choo, S.J. et al. Long-term outcomes of mechanical valve replacement in patients with atrial fibrillation: impact of the maze procedure.Circulation. 2012; 125: 2071-2080.

32. Stroke Prevention in Atrial Fibrillation Investigators: Prospective identification of patients with nonvalvular atrial fibrillation at low risk during treatment with aspirin: Stroke prevention in Atrial Fibrillation III Study. Circulation 1997;96:1-28.

33. Kim, J.B., Bang, J.H., Jung, S.H., Choo, S.J., Chung, C.H., and Lee, J.W. Left atrial ablation versus biatrial ablation in the surgical treatment 
of atrial fibrillation. (discussion 1404, 1395)Ann Thorac Surg.2011; 92: 1397-1404.

34. Levine HJ. Which atrial fibrillation patients should be on chronic anticoagulation? J Cardiovasc Med 1981;6:483-7.

35. Bando, K., Kasegawa, H., Okada, Y., Kobayashi, J., Kada, A., Shimokawa, T. et al. Impact of preoperative and postoperative atrial fibrillation on outcome after mitral valvuloplasty for nonischemic mitral regurgitation. J Thorac Cardiovasc Surg. 2005; 129: 1032-1040

36. Coulshed N, Epstein EJ, McKendrick CS, Galloway RW, Walker E. Systemic embolism in mitral valve disease. $\mathrm{Br}$ Heart $\mathrm{J}$ 1970;32:26-34.

37. Bando, K., Kobayashi, J., Kosakai, Y., Hirata, M., Sasako, Y., Nakatani, S. et al. Impact of Cox maze procedure on outcome in patients with atrial fibrillation and mitral valve disease. J Thorac Cardiovasc Surg. 2002; 124: 575-583

38. Medi, C., Hankey, G.J., and Freedman, S.B. Stroke risk and antithrombotic strategies in atrial fibrillation. Stroke. 2010; 41: 2705-2713.

39. Karen L. Furie, MD, MPH; Mahesh V. Jayaraman, MD. 2018 Guidelines for the Early Management of Patients With Acute Ischemic Stroke. Stroke. 2018;49:509-510.

40. Sacco RL, Adams R, Albers G, Alberts MJ, Benavente $\mathrm{O}$, Furie $\mathrm{K}$, et al. Guidelines for prevention of stroke in patients with ischemic stroke or transient ischemic attack: A statement for healthcare professionals from the American Heart Association/ American Stroke Association Council on Stroke: Cosponsored by the Council on Cardiovascular Radiology and Intervention: The American Academy of Neurology affirms the value of this guideline. Stroke 2006;37:577-617.

41. Baek MJ, Na CY, Oh SS, Lee CH, Kim JH, Seo HJ, Park SW, Kim WS. Surgical treatment of chronic atrial fibrillation combined with rheumatic mitral valve disease: Effects of the cryo-maze procedure and predictors for late recurrence. Eur J Cardiothorac Surg. 2006 Nov;30(5):728-36.

42. Practice Guidelines AHA/ASA publish advisory on oral antithrombotics for stroke prevention in nonvalvular artial fibrillation. Am Fam Physician. 2013 May 15;87(10):732-3.

43. Akdemir I, Dagdelen S, Yuce M, Davutoglu V, Akcay M, Akdemir N, et al. Silent brain infarction in patients with rheumatic mitral stenosis. Jpn Heart J 2002;43:137-44.

44. Leary MC1, Saver JL. Annual incidence of first silent stroke in the United States: a preliminary estimate. Cerebrovasc Dis. 2003; 16(3):280-5.

Iung B, Leenhardt A, Extramiana F. Management of atrial fibrillation in patients with rheumatic mitral stenosis. Heart. 2018 Feb 16. pii: heartjnl. 2017: 311-425. 